\title{
Altered glycosylation associated with dedifferentiation of hepatocellular carcinoma: a lectin microarray-based study
}

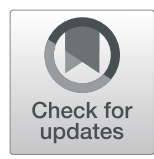

\author{
Hiroomi Takayama1* ${ }^{1 *}$, Masayuki Ohta ${ }^{1,2}$, Yukio Iwashita', Hiroki Uchida', Yuki Shitomi', Kazuhiro Yada' and
} Masafumi Inomata'

\begin{abstract}
Background: Altered glycosylation associated with hepatocellular carcinoma (HCC) is well documented. However, few reports have investigated the association between dedifferentiation and glycosylation. Therefore, the aim of this study was to analyze glycosylation associated with dedifferentiation of HCC within the same nodule and to investigate glycosyltransferase related to the glycosylation.
\end{abstract}

Methods: We analyzed resected HCC specimens $(n=50)$ using lectin microarray to comprehensively and sensitively analyze glycan profiles, and identify changes to glycosylation between well- and moderately-differentiated components within the same nodule. Moreover, we performed immunohistochemical staining of mannosyl(a-1,3)-glycoprotein $\beta-1,2-N$-acetylglucosaminyltransferase (MGAT1), which is an essential glycosyltransferase that converts high-mannose glycans to complex- or hybrid-type N-glycans.

Results: Four lectins from Narcissus pseudonarcissus agglutinin (NPA), Concanavalin A, Galanthus nivalis agglutinin, and Calystegia sepium agglutinin were significantly elevated in moderately-differentiated components of HCC compared with well-differentiated components, and all lectins showed binding specificity to high-mannose glycans. Therefore, these structures were represented to a greater extent in moderately-differentiated components than in well-differentiated ones. Immunohistochemical staining revealed significantly increased NPA expression and decreased MGAT1 expression in moderately-differentiated components. Low MGAT1 expression in moderatelydifferentiated components of tumors was associated with intrahepatic metastasis and had tendency for poor prognosis.

Conclusion: Dedifferentiation of well-differentiated HCC is associated with an increase in high-mannose glycans. MGAT1 may play a role in the dedifferentiation of HCC.

Keywords: Hepatocellular carcinoma, Dedifferentiation, High-mannose glycan, Lectin microarray, Mannosyl(a-1,3)-glycoprotein $\beta-1,2-N$-acetylglucosaminyltransferas

\section{Background}

Hepatocellular carcinoma (HCC) is a common cancer with poor prognosis $[1,2]$. Liver cancer is the sixth most

\footnotetext{
* Correspondence: t-1603@oita-u.ac.jp

${ }^{1}$ Department of Gastroenterological and Pediatric Surgery, Oita University Faculty of Medicine, 1-1 Idaigaoka, Hasama-machi, Yufu, Oita 879-5593, Japan Full list of author information is available at the end of the article
}

common type of cancer worldwide, and the fourth most common cause of cancer death [3]. HCC accounts for the most primary liver cancer. Therefore, exploring the mechanism of tumor progression and improving treatments for $\mathrm{HCC}$ are urgent requirements.

Glycosylation is involved in many essential biological processes such as cell differentiation, proliferation, and

(C) The Author(s). 2020 Open Access This article is licensed under a Creative Commons Attribution 4.0 International License, which permits use, sharing, adaptation, distribution and reproduction in any medium or format, as long as you give appropriate credit to the original author(s) and the source, provide a link to the Creative Commons licence, and indicate if changes were made. The images or other third party material in this article are included in the article's Creative Commons licence, unless indicated otherwise in a credit line to the material. If material is not included in the article's Creative Commons licence and your intended use is not permitted by statutory regulation or exceeds the permitted use, you will need to obtain permission directly from the copyright holder. To view a copy of this licence, visit http://creativecommons.org/licenses/by/4.0/ The Creative Commons Public Domain Dedication waiver (http://creativecommons.org/publicdomain/zero/1.0/) applies to the data made available in this article, unless otherwise stated in a credit line to the data. 
adhesion; immune response; and receptor activation. However, aberrant glycosylation results in many dysfunctions and diseases $[4,5]$. For example, in many kinds of cancer, aberrant glycosylation such as fucosylation and sialylation, as well as altered expression of glycosyltransferase, which modulates glycosylation, have been reported [6-11]. In HCC, altered glycosylation, such as that of alpha fetoprotein (AFP)-L3-a core fucosylated AFP enhanced by fucosyltransferase-is well known [12, 13]. Moreover, fucosylated haptoglobin and fucosylated kininogen were also reported to be candidates for biological markers of HCC $[14,15]$.

Lectin microarray is a method capable of analyzing glycan profiles comprehensively and sensitively with 45 lectins utilizing lectin specificity to detect specific structures of glycans $[16,17]$. Using this method, we reported the association between Agaricus bisporus agglutinin and colon cancer recurrence as well as between Bauhinia purpurea lectin and gastric cancer recurrence [18, 19]. In addition, we also reported that fucosylation was associated with the malignant transformation of intraductal papillary mucinous neoplasm of the pancreas [20].

HCC often comprises differentiated components-the so-called "nodule-in-nodule" appearance-which suggests multistep development [21, 22]. There have been several reports of dedifferentiation in $\mathrm{HCC}$ and altered gene expression of CAP, HSP70, p53, and $\beta$-catenin [23-25]. However, there are few reports of altered glycosylation associated with dedifferentiation. Therefore, in this study, we investigated glycosylation associated with the dedifferentiation of HCC within the same nodule, and glycosyltransferase related to the glycosylation.

\section{Methods}

\section{Patients and tissue samples}

We collected the clinical records and surgical specimens who underwent curative resection for $\mathrm{HCC}$ at the Department of Gastroenterological and Pediatric Surgery, Oita University Faculty of Medicine, from January 2006 to December 2015. Patients who underwent preoperative treatments such as transarterial chemoembolization and radiofrequency ablation were excluded from the study. In addition, the tumor size was limited to $3-10 \mathrm{~cm}$ to analyze well- and moderately-differentiated components within the same nodule. Well- and moderatelydifferentiated components in the same nodule were histologically distinguished by two pathologists on the basis of typical characteristics using hematoxylin and eosin (HE) stain according to the General Rules for the Clinical and Pathological Study of Primary Liver Cancer [26]. Finally, 50 patients were enrolled in the study. We also collected pathological data including number of tumors, tumor size, intrahepatic metastasis, portal vein invasion, venous invasion, arterial invasion, biliary invasion, capsule
Table 1 Differences in lectin microarray signal intensity between well- and moderately-differentiated components of $\mathrm{HCC}(n=50)$

\begin{tabular}{|c|c|c|c|c|c|c|c|}
\hline \multirow{2}{*}{$\begin{array}{l}\text { Lectin } \\
\text { LTL }\end{array}$} & \multicolumn{3}{|c|}{ Well-differentiated } & \multicolumn{3}{|c|}{ Moderately-differentiated } & \multirow{2}{*}{$\begin{array}{l}\boldsymbol{P} \text {-value } \\
0.518\end{array}$} \\
\hline & $\overline{14.6}$ & \pm & 0.8 & 13.9 & \pm & 1.1 & \\
\hline PSA & 48.4 & \pm & 2.6 & 52.5 & \pm & 3.9 & 0.406 \\
\hline LCA & 73.8 & \pm & 3.3 & 78.6 & \pm & 4.1 & 0.622 \\
\hline UEA-I & 10.0 & \pm & 1.5 & 8.1 & \pm & 1.3 & 0.285 \\
\hline AOL & 81.7 & \pm & 7.2 & 72.7 & \pm & 6.5 & 0.157 \\
\hline AAL & 101.9 & \pm & 6.7 & 89.9 & \pm & 6.8 & 0.076 \\
\hline MAL-I & 11.4 & \pm & 0.9 & 9.6 & \pm & 1.1 & 0.095 \\
\hline SNA & 232.6 & \pm & 9.0 & 223.2 & \pm & 9.9 & 0.431 \\
\hline SSA & 233.6 & \pm & 11.4 & 222.1 & \pm & 11.5 & 0.215 \\
\hline TJA-I & 319.2 & \pm & 13.4 & 303.7 & \pm & 16.7 & 0.224 \\
\hline PHA(L) & 4.3 & \pm & 0.7 & 4.7 & \pm & 0.7 & 0.461 \\
\hline ECA & 6.6 & \pm & 1.0 & 5.5 & \pm & 0.7 & 0.572 \\
\hline RCA120 & 112.7 & \pm & 8.6 & 117.4 & \pm & 16.7 & 0.267 \\
\hline PHA(E) & 82.9 & \pm & 5.9 & 77.9 & \pm & 5.4 & 0.958 \\
\hline DSA & 323.0 & \pm & 10.6 & 304.7 & \pm & 7.9 & 0.112 \\
\hline GSL-II & 5.7 & \pm & 1.4 & 7.4 & \pm & 2.3 & 0.737 \\
\hline NPA & 137.7 & \pm & 11.3 & 149.8 & \pm & 12.6 & $0.049^{*}$ \\
\hline ConA & 212.6 & \pm & 15.4 & 243.2 & \pm & 19.2 & $0.008^{*}$ \\
\hline GNA & 63.2 & \pm & 4.0 & 73.1 & \pm & 4.6 & $0.028^{*}$ \\
\hline $\mathrm{HHL}$ & 23.3 & \pm & 1.7 & 25.6 & \pm & 2.4 & 0.824 \\
\hline ACG & 126.3 & \pm & 9.6 & 115.8 & \pm & 8.3 & 0.275 \\
\hline TxLC-I & 48.1 & \pm & 5.1 & 44.9 & \pm & 4.4 & 0.553 \\
\hline BPL & 11.4 & \pm & 1.4 & 13.8 & \pm & 1.7 & 0.338 \\
\hline TJA-II & 45.7 & \pm & 5.1 & 43.9 & \pm & 3.8 & 0.735 \\
\hline EEL & 3.4 & \pm & 0.6 & 3.3 & \pm & 0.6 & 0.781 \\
\hline$A B A$ & 93.4 & \pm & 5.3 & 96.3 & \pm & 8.0 & 0.595 \\
\hline LEL & 393.0 & \pm & 7.6 & 393.0 & \pm & 8.4 & 0.757 \\
\hline STL & 490.4 & \pm & 13.3 & 498.9 & \pm & 11.9 & 0.472 \\
\hline UDA & 359.6 & \pm & 7.5 & 352.0 & \pm & 8.0 & 0.434 \\
\hline PWM & 7.8 & \pm & 0.8 & 8.2 & \pm & 1.0 & 0.648 \\
\hline Jacalin & 132.5 & \pm & 4.5 & 137.4 & \pm & 5.6 & 0.443 \\
\hline PNA & 3.1 & \pm & 0.5 & 2.9 & \pm & 0.5 & 0.825 \\
\hline WFA & 10.7 & \pm & 1.3 & 10.5 & \pm & 1.1 & 0.992 \\
\hline ACA & 56.7 & \pm & 2.2 & 61.2 & \pm & 2.8 & 0.118 \\
\hline MPA & 32.3 & \pm & 2.5 & 30.8 & \pm & 2.3 & 0.636 \\
\hline HPA & 25.3 & \pm & 1.9 & 26.3 & \pm & 2.3 & 0.731 \\
\hline VVA & 6.2 & \pm & 0.9 & 6.2 & \pm & 0.9 & 0.831 \\
\hline DBA & 6.9 & \pm & 0.9 & 7.1 & \pm & 1.5 & 0.314 \\
\hline SBA & 6.2 & \pm & 1.0 & 6.3 & \pm & 0.9 & 0.688 \\
\hline Calsepa & 342.9 & \pm & 23.7 & 363.5 & \pm & 23.1 & $0.039^{*}$ \\
\hline PTL-I & 4.2 & \pm & 0.8 & 4.9 & \pm & 0.7 & 0.170 \\
\hline MAH & 19.5 & \pm & 1.0 & 16.9 & \pm & 1.0 & 0.073 \\
\hline WGA & 149.8 & \pm & 5.8 & 147.1 & \pm & 5.3 & 0.612 \\
\hline GSL-I-A4 & 8.9 & \pm & 1.1 & 10.1 & \pm & 1.3 & 0.659 \\
\hline GSL-I-B4 & 8.3 & \pm & 0.9 & 8.0 & \pm & 1.0 & 0.800 \\
\hline
\end{tabular}

Mean \pm SEM, ${ }^{*} P<0.05$ (statistically significant) 
invasion, and serosal invasion. All clinical data and tissue samples were collected after obtaining informed consent from the included patients.

\section{Sample preparation and lectin microarray}

Fifty tissue samples were prepared for laser microdissection by fixing in formalin, embedding in paraffin, then sectioning at a thickness of $5 \mu \mathrm{m}$. The sections were placed on dedicated glass slides and stained with HE after deparaffinizing. Well- and moderately-differentiated components were extracted from the same nodule using laser microdissection. Each section was $5 \times 10^{6} \mu \mathrm{m}^{2}$ to equalize the tissue volume. Lectin microarray was performed as previously described $[18,20]$. In brief, sections were sonicated with Bioruptor UCW-310 (Cosmobio, Co., Ltd., Tokyo, Japan). Proteins were extracted with Zeba Desalt Spin Columns (Thermo Scientific Ltd., Rockford, IL, USA), labeled with cyanine 3 fluorescent dye, and transferred onto Lectip (GlycoTechnica Ltd., Yokohama, Japan) with seven wells containing 45 lectins. The list of lectins and their specificities to glycans is available from the manufacturer [27]. Fluorescent images were obtained with the Glycostation Reader 1200 (GlycoTechnica Ltd.) using the evanescent-wave excitation method [28]. Data were analyzed using Glycostation Tool Pro Suite 1.5 (GlycoTechnica Ltd.). Signal intensities were measured in triplicate and normalized across the 45 lectins by setting the average intensity of the 45 lectins to 100 .

\section{Lectin staining and immunohistochemistry}

Fifty formalin-fixed and paraffin-embedded tissues were sectioned at a thickness of $3 \mu \mathrm{m}$ for lectin staining and immunohistochemistry, as described previously $[18,20]$. For lectin staining, the sections were incubated with biotinylated Narcissus pseudonarcissus agglutinin (NPA) (BA-8006-1, EY Laboratories, Inc., San Mateo, CA, USA) and then processed using the VECTASTAIN Elite ABC kit (Vector Laboratories, Inc., Burlingame, CA, USA) according to the manufacturer's instructions. For immunohistochemical analysis, mannosyl $(\alpha-1,3-)$-glycoprotein $\beta$ 1,2- $N$-acetylglucosaminyltransferase (MGAT1) (151031-AP, Proteintech, Inc., Chicago, IL, USA)—an essential glycosyltransferase that converts high-mannose type $N$ glycans to complex- or hybrid-type $N$-glycans-was used as the primary antibody. Staining intensity was scored in duplicate by two pathologists as follows: negative, 0 point; weak $(<10 \%$ positive staining $), 1$ point; moderate (10-50\% positive staining), 2 points; and strong (> 50\% positive staining), 3 points $[29,30]$. The clinicopathological outcomes of the patients were blinded to the pathologists. In case of discrepancy in provisional scores between the pathologists, the final scores were determined through their consensus. On the basis of scores, tumors were divided into two groups with low (score 0

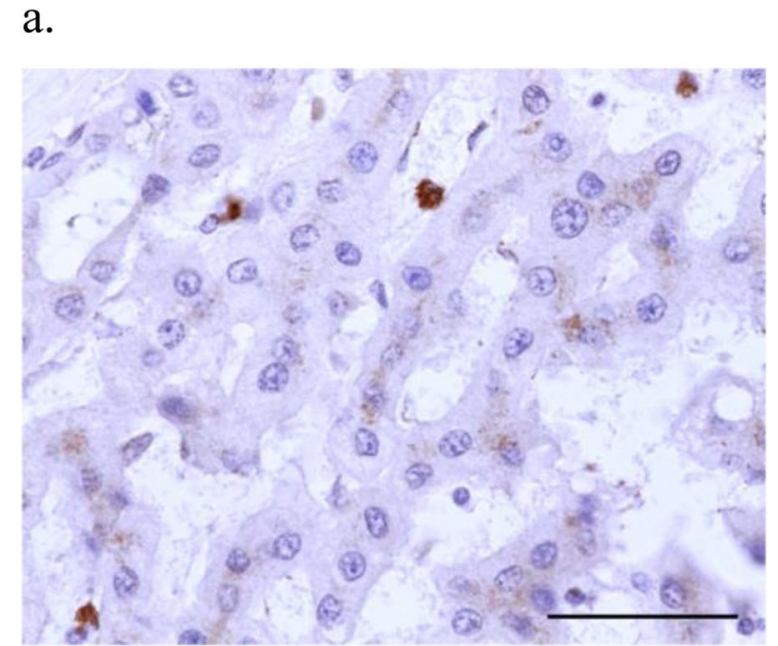

b.

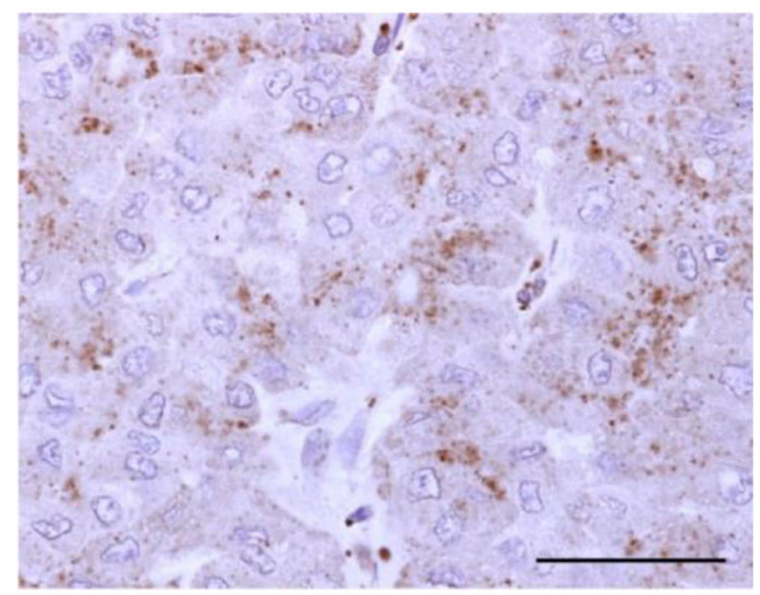

c.

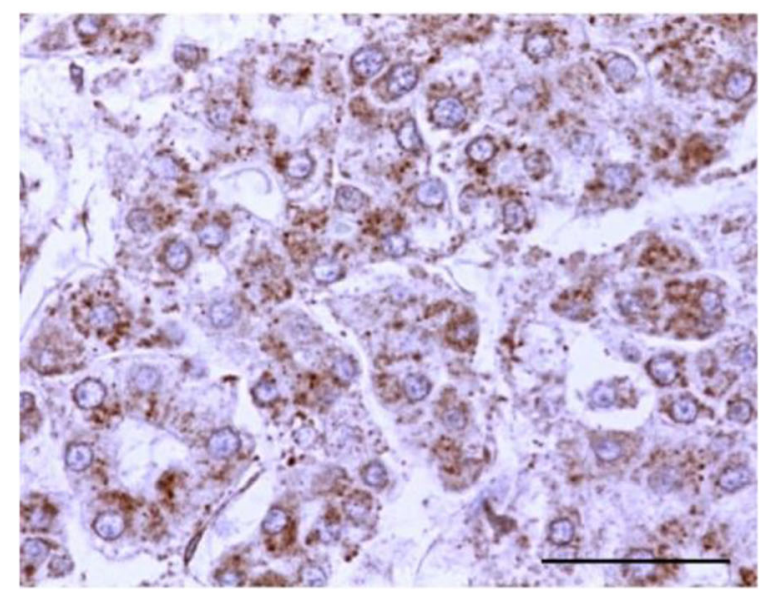

Fig. 1 Representative lectin staining of NPA in HCC specimens ( $\times$ 400). Intensity: (a) weak (1 point), (b) moderate (2 points), and (c) strong (3 points). No specimen showed negative staining (0 point). Scale bar indicates $50 \mu \mathrm{m}$ 
or 1) or high (score 2 or 3) MGAT1 expression in the moderately-differentiated components. Overall survival (OS) and disease-free survival (DFS) were estimated, and patients were also divided into within $(n=27)$ and beyond $(n=23)$ the Milan criteria groups for analysis [31].

\section{Statistical analysis}

All statistical analyses were performed using SPSS, version 20 statistical software (SPSS Inc., Chicago, IL, USA). Data were expressed as the mean \pm standard error of the mean (SEM). Differences between well- and moderately-differentiated components in lectin microarray signal and staining intensities were analyzed by Wilcoxon signed rank test. Other categorical variables were analyzed using Fisher's probability test, and continuous variables using Mann-Whitney $U$ test. OS and DFS were analyzed using the Kaplan-Meier method, and compared using the log-rank test. The level of probability was set at $P<0.05$ as statistically significant.

\section{Results}

A total of 45 lectin signal patterns were analyzed comprehensively between well- and moderately-differentiated components of HCC. Among them, four lectins of NPA, Concanavalin A (ConA), Galanthus nivalis agglutinin (GNA), and Calystegia sepium agglutinin (Calsepa) were significantly increased in moderately-differentiated components compared with well-differentiated components (Table 1). All the lectins showed specificity to highmannose glycan structures and none were significantly decreased by dedifferentiation.

Representative staining of NPA and MGAT1 is presented in Figs. 1 and 2. NPA staining scores were significantly increased in moderately-differentiated components compared with those in well-differentiated components $(p=0.002)$ (Fig. 3). In contrast, MGAT1 staining scores were significantly decreased in moderately-differentiated components compared with those in well-differentiated components $(p<0.001)$ (Fig. 4).

Low and high MGAT1 expression in the moderately differentiated components was noted in 12 and 38 patients, respectively. Table 2 presents the associations between the clinicopathological findings and MGAT1 expression levels. Intrahepatic metastasis alone was significantly correlated with low MGAT1 expression group $(p=0.031)$. OS analysis revealed no significant differences between the low and high MGAT1 expression groups $(p=0.249)$; however, the prognosis tended to be poor in the low MGAT1 expression group (Fig. 5a). DFS showed neither significant differences nor any trend $(p=0.446$, Fig. $5 b)$. Similarly, patients in the within the Milan criteria group, there were no significant differences in OS $(p=0.796)$ and DFS $(p=0.145)$ between patients with low and high MGAT1 expression. a.

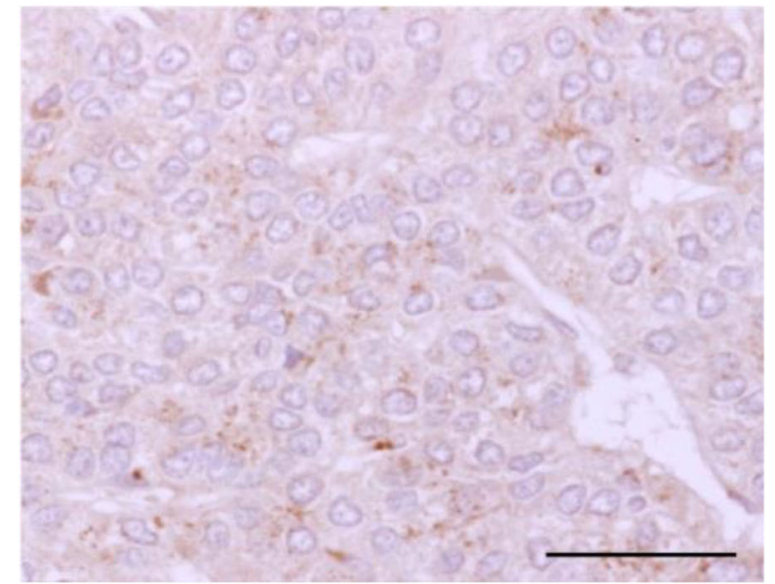

b.

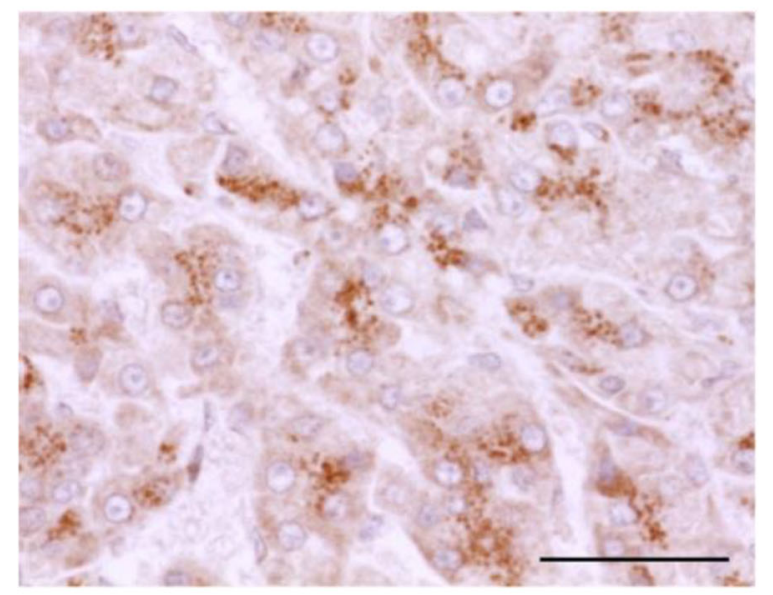

c.

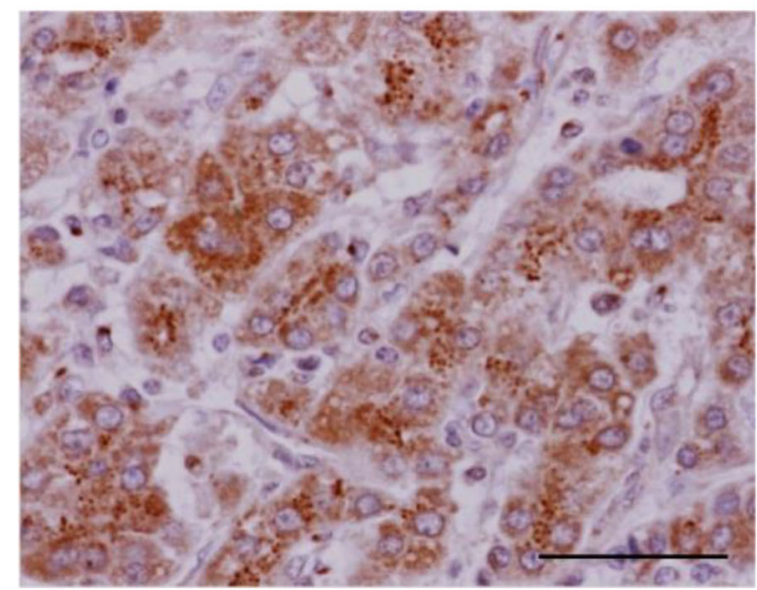

Fig. 2 Representative immunohistochemical staining of MGAT1 in HCC specimens ( $\times 400)$. Intensity: (a) weak (1 point), (b) moderate (2 points), and (c) strong (3 points). No specimen showed negative staining (0 point). Scale bar indicates $50 \mu \mathrm{m}$ 


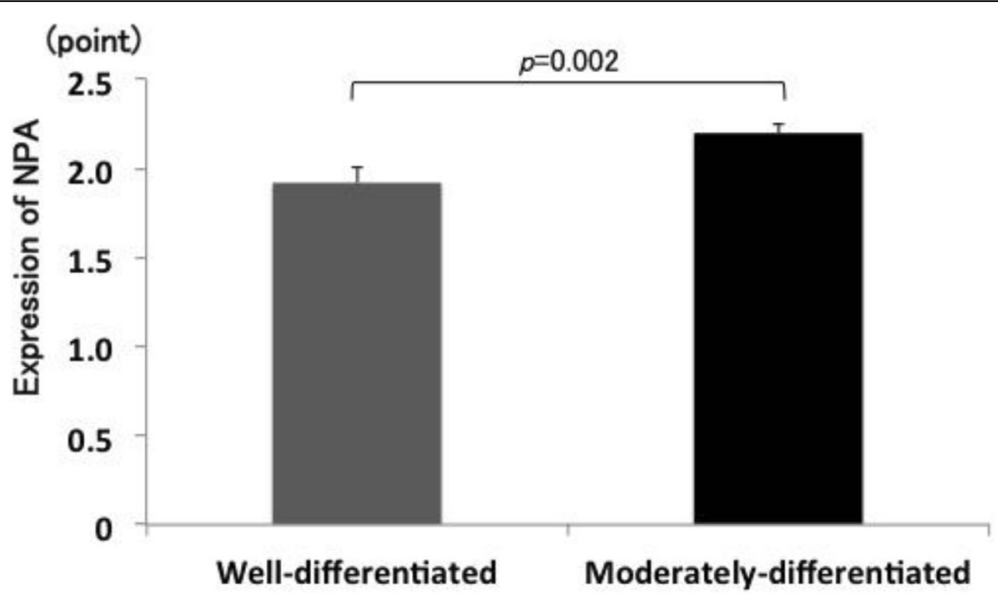

Fig. 3 Differences in NPA staining scores between well- and moderately-differentiated components of HCC

Meanwhile, in patients in the beyond the Milan criteria group, those with low MGAT1 expression group showed significantly poorer prognosis in terms of OS than those with high MGAT1 expression group ( $p=0.045$, Fig. 6a). DFS showed no significant differences between the groups ( $p=0.508$, Fig. 6b).

\section{Discussion}

The present study is the first to demonstrate altered glycosylation associated with dedifferentiation in HCC using lectin microarray. The signal intensities of four lectins, including NPA, ConA, GNA, and Calsepa, were significantly increased in moderately-differentiated components compared with those in well-differentiated components. Since lectins bind to glycan structures, these structures are in fact represented to a greater extent in cells. All four lectins showed binding specificity to high-mannose glycan structures, thereby the glycans were significantly increased in moderately-differentiated components compared with well-differentiated components in HCC. NPA-one of the elevated lectins that binds high-mannose glycans-has been reported to be increased in gastric cancer cell lines [32]. Therefore, we performed NPA staining to confirm elevated high-mannose glycan expression and demonstrated that increased high-mannose glycans expression was associated with decreased MGAT1 expression.

Among high-mannose structures, NPA binds to

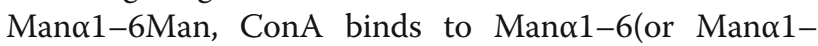
3)Man, GNA binds to Man 1 1-3Man, and Calsepa binds to Man2-6 and $N$-glycans including bisecting GlcNAc [16]. All examined lectins showed specificity to highmannose glycan structures. High-mannose-type glycans, which are a type of $N$-glycan, are attached to proteins and play essential roles in the transfer of correctly folded proteins from the endoplasmic reticulum to the Golgi apparatus [33]. Several enzymes involved in $N$-glycan processing are candidates for the mechanism of increased high-mannose glycans. MGAT1 is a key

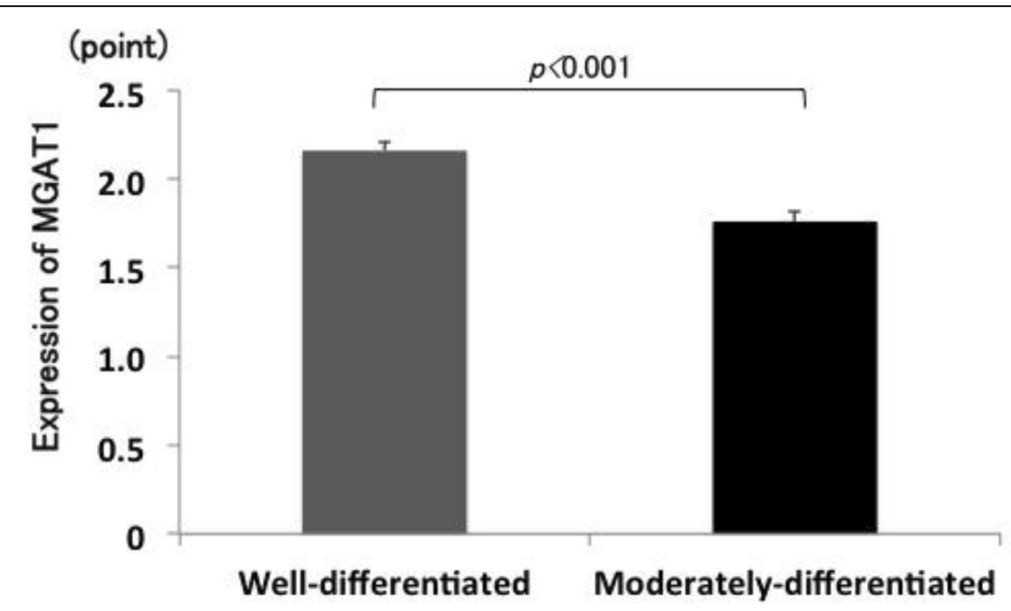

Fig. 4 Differences in MGAT1 staining scores between well- and moderately-differentiated components of HCC 
Table 2 Association between the clinicopathological characteristics and MGAT1 expression in moderatelydifferentiated components of HCC

\begin{tabular}{|c|c|c|c|c|c|}
\hline \multirow{2}{*}{$\begin{array}{l}\text { Clinicopathological } \\
\text { characteristics }\end{array}$} & & \multirow{2}{*}{$\begin{array}{l}\text { Total } \\
\mathrm{n}= \\
50\end{array}$} & \multicolumn{2}{|c|}{ MGAT1 expression } & \multirow{2}{*}{$\begin{array}{l}\boldsymbol{P} \text { - } \\
\text { value }\end{array}$} \\
\hline & & & $\begin{array}{l}\text { High }(\boldsymbol{n}= \\
\text { 38) }\end{array}$ & $\begin{array}{l}\text { Low }(\boldsymbol{n}= \\
12)\end{array}$ & \\
\hline Age (years) & & & $72.5 \pm 1.3$ & $71.3 \pm 2.0$ & 0.459 \\
\hline \multirow[t]{2}{*}{ Sex } & Male & 38 & 31 & 7 & \multirow[t]{2}{*}{0.100} \\
\hline & Female & 12 & 7 & 5 & \\
\hline Number of tumor & & & $1.7 \pm 0.3$ & $1.3 \pm 0.3$ & 0.176 \\
\hline Tumor size (mm) & & & $45.3 \pm 3.7$ & $59.7 \pm 7.9$ & 0.086 \\
\hline \multirow{2}{*}{$\begin{array}{l}\text { Intrahepatic } \\
\text { metastasis }\end{array}$} & - & 40 & 33 & 7 & \multirow[t]{2}{*}{$0.031^{*}$} \\
\hline & + & 10 & 5 & 5 & \\
\hline \multirow[t]{2}{*}{ Portal vein invasion } & - & 43 & 34 & 9 & \multirow[t]{2}{*}{0.208} \\
\hline & + & 7 & 4 & 3 & \\
\hline \multirow[t]{2}{*}{ Venous invasion } & - & 40 & 31 & 9 & \multirow[t]{2}{*}{0.619} \\
\hline & + & 10 & 7 & 3 & \\
\hline \multirow[t]{2}{*}{ Arterial invasion } & - & 49 & 37 & 12 & \multirow[t]{2}{*}{0.570} \\
\hline & + & 1 & 1 & 0 & \\
\hline \multirow[t]{2}{*}{ Biliary invasion } & - & 49 & 37 & 12 & \multirow[t]{2}{*}{0.570} \\
\hline & + & 1 & 1 & 0 & \\
\hline \multirow[t]{2}{*}{ Capsule invasion } & - & 26 & 21 & 5 & \multirow[t]{2}{*}{0.411} \\
\hline & + & 24 & 17 & 7 & \\
\hline \multirow[t]{2}{*}{ Serosal invasion } & - & 41 & 33 & 8 & \multirow[t]{2}{*}{0.113} \\
\hline & + & 9 & 5 & 4 & \\
\hline \multirow[t]{2}{*}{ Milan criteria } & Within & 27 & 20 & 7 & \multirow[t]{2}{*}{1.000} \\
\hline & Beyond & 23 & 18 & 5 & \\
\hline \multirow[t]{2}{*}{ Recurrence } & - & 26 & 8 & 5 & \multirow[t]{2}{*}{0.256} \\
\hline & + & 24 & 30 & 7 & \\
\hline \multirow[t]{2}{*}{ Death } & - & 41 & 26 & 6 & \multirow[t]{2}{*}{0.309} \\
\hline & + & 9 & 12 & 6 & \\
\hline
\end{tabular}

Mean \pm SEM, ${ }^{*} P<0.05$ (statistically significant)

glycosyltransferase that initiates the conversion of highmannose-type glycans to complex- and hybrid-type $\mathrm{N}$ glycans and is significantly associated with human homeostasis [34]. Recently, MGAT1 has also been proposed to play a substantial role in tumor immunity [35]. Lack of this enzyme results in an abundance of highmannose glycans [36]. Decreased expression of the MGAT1 gene in breast cancer tissue was associated with poor prognosis [37]. Similarly, decreased MGAT1 expression was observed in HCCLM3 cells, which show a higher metastatic potential than Hep3B cells [38]. Also, decreased expression of mannosidase alpha class $1 \mathrm{~A}$ member 1 (MAN1A1), which trims $\alpha$-1,2-linked mannose residues from Man9 high-mannose glycan in the Golgi apparatus, could also result in an increase in highmannose glycans, and mannosyltransferase may increase the levels of high-mannose glycans. However, few

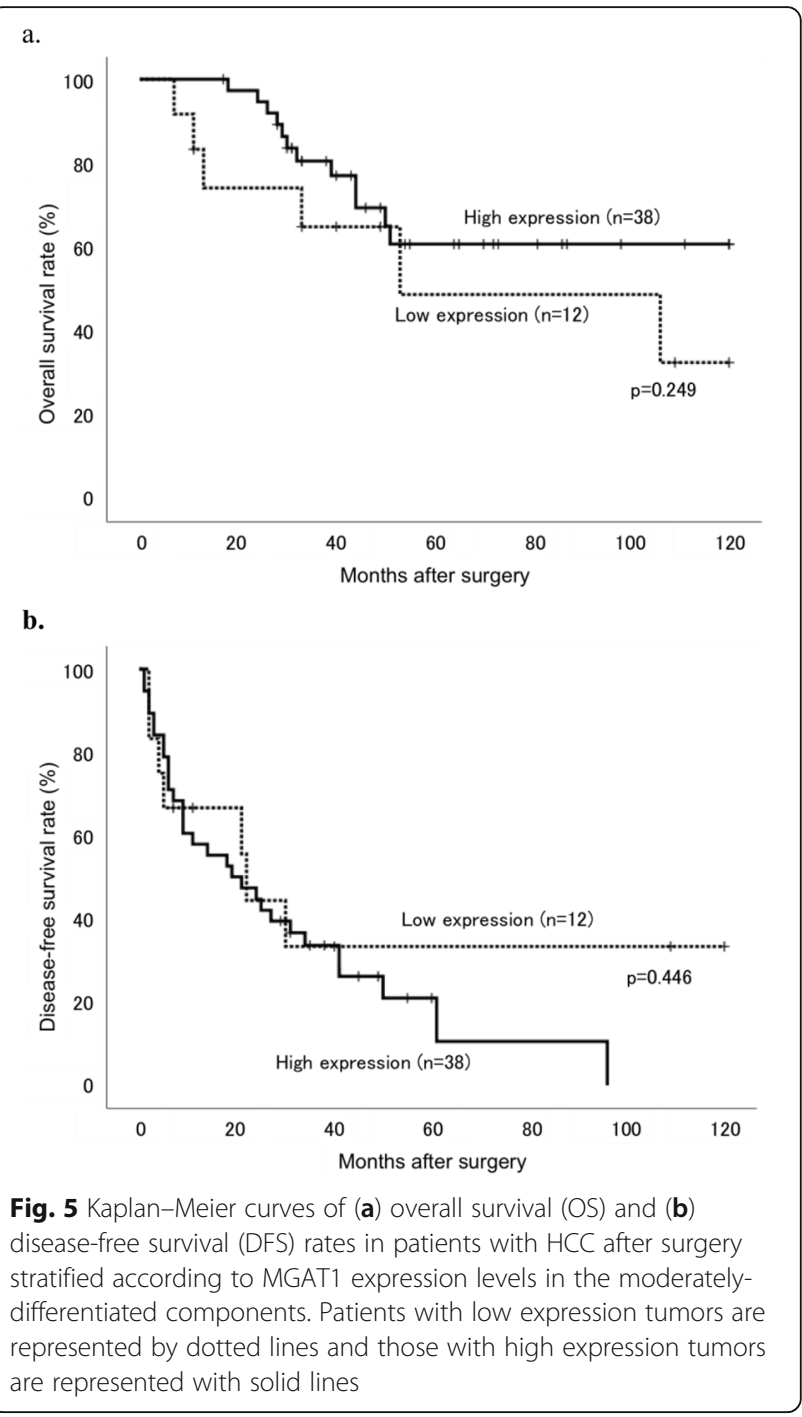

studies have reported associations between enzymes and cancer. In the present study, MGAT1 expression decreased with dedifferentiation of HCC, potentially resulting in an increase in the levels of high-mannose glycans. In addition, low MGAT1 expression in moderatelydifferentiated components of tumors was associated with intrahepatic metastasis and tendency of poor prognosis. In patients within the Milan criteria, there were no significant differences in OS and DFS between the low and high MGAT1 expression groups, but there were significant differences in OS in patients beyond the Milan criteria.

Many studies have reported increases in high-mannose glycans in cancer, including in HCC model rats [39]. In addition, an epithelial-mesenchymal transition (EMT)induced HCC cell line, that indicates a metastatic potential, also showed an increase in high-mannose glycans compared with an HCC cell line without EMT induction [40]. Other studies have shown abundant expression of 


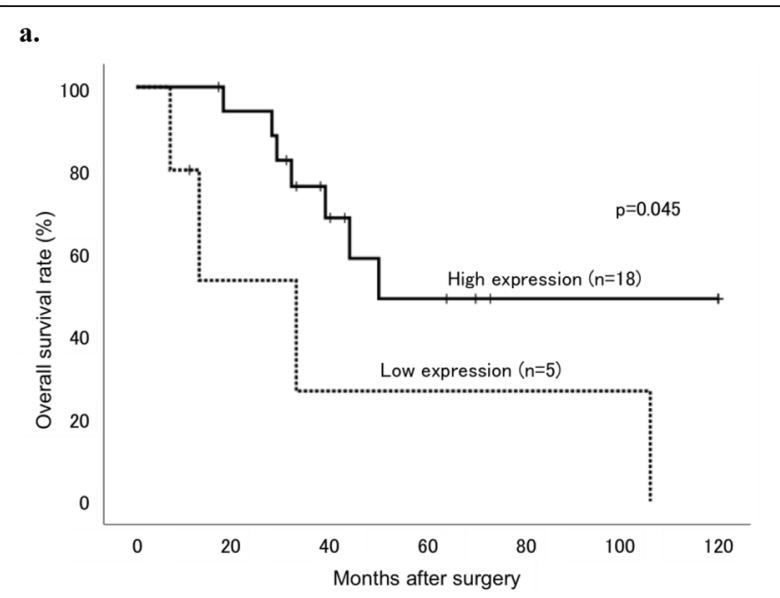

b.

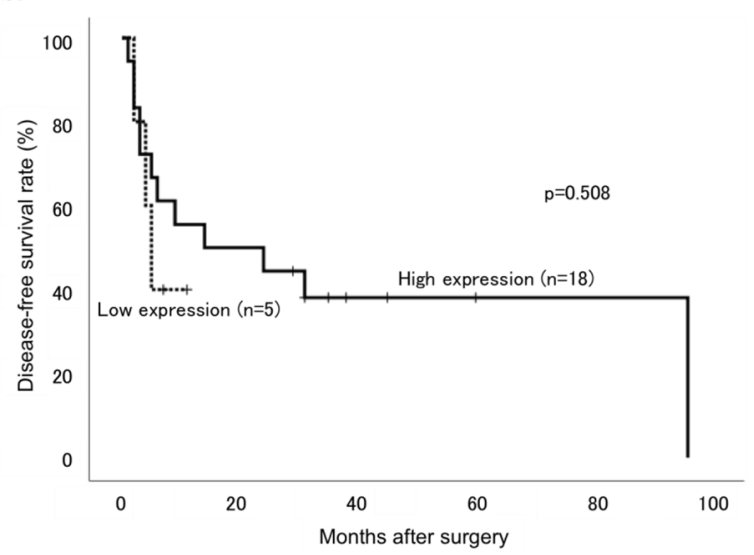

Fig. 6 Kaplan-Meier curves of (a) OS and (b) DFS rates in HCC patients beyond the Milan criteria stratified according to MGAT1 expression levels in the moderately-differentiated components. Patients with low expression tumors are represented by dotted lines and those with high expression tumors are represented with solid lines

high-mannose glycans in colorectal cancer cell lines including moderately- and poorly-differentiated cell lines and metastatic cell lines, as well as in colorectal cancer tissues [41, 42]. Glycans were also increased in breast cancer tissues compared with normal tissues. Furthermore, stage II and III cancer tissues showed significantly higher glycan expression than stages 0 and I tissues [43]. In the present study, high-mannose glycans were increased according to HCC dedifferentiation; therefore, increased high-mannose glycan expression may be associated with high-grade HCC malignancy.

Our study has some limitations. First, the number of specimens studied was small. Second, we did not assess MGAT1 function in HCC dedifferentiation. Finally, we did not examine the expression of other enzymes involved in $\mathrm{N}$-glycan processing. Therefore, further studies are necessary. If demonstrated to have an apparent function in HCC dedifferentiation, MGAT1 can serve as a potential target for HCC treatment in the future.

\section{Conclusions}

In conclusion, dedifferentiation of well-differentiated HCC is associated with increased high-mannose glycans. Furthermore, MGAT1 may play a role in HCC dedifferentiation.

\section{Abbreviations}

AFP: Alpha fetoprotein; Calsepa: Calystegia sepium agglutinin; ConA: Concanavalin A; DFS: Disease-free survival; EMT: Epithelialmesenchymal transition; GNA: Galanthus nivalis agglutinin; HCC: Hepatocellular carcinoma; HE: Hematoxylin and eosin; MGAT1: Mannosyl(a-1,3-)-glycoprotein $\beta-1,2-N$-acetylglucosaminyltransferase; NPA: Narcissus pseudonarcissus agglutinin; OS: Overall survival; SEM: Standard error of the mean

\section{Acknowledgments}

We would like to thank Ms. Yuiko Aso and Mayumi Wada for their technical assistance with the experiments.

\section{Authors' contributions}

$\mathrm{HT}, \mathrm{MO}$, and $\mathrm{Yl}$ conceived and designed the study. HT, YS, and KY collected and analyzed the data. $\mathrm{HT}, \mathrm{MO}, \mathrm{Yl}, \mathrm{HU}$, and MI wrote the manuscript. All authors have read and approved the final manuscript.

\section{Funding}

This work was supported by JSPS KAKENHI Grant Number JP17K16572. The funding body was not involved in the design of this study and collection, analysis, and interruption of data and in writing the manuscript.

\section{Availability of data and materials}

The datasets used and/or analyzed during the current study are available from the corresponding author upon reasonable request.

\section{Ethics approval and consent to participate}

This study was approved by the ethics committee of Oita University Faculty of Medicine (\#1339). The written comprehensive agreement with use of tissue samples for research was obtained from each patient before the operation. The informed consent in this study was obtained by the opt-out method, which the ethics committee approved, because the study contains many former tissue samples.

\section{Consent for publication}

Not applicable.

\section{Competing interests}

The authors have no competing interests.

\section{Author details}

'Department of Gastroenterological and Pediatric Surgery, Oita University Faculty of Medicine, 1-1 Idaigaoka, Hasama-machi, Yufu, Oita 879-5593, Japan. ${ }^{2}$ Global Oita Medical Advanced Research Center for Health, Oita University, Oita, Japan.

Received: 6 September 2019 Accepted: 28 February 2020

Published online: 06 March 2020

\section{References}

1. Kokudo N, Hasegawa K, Akahane M, Igaki H, Izumi N, Ichida T, et al. Evidence-based clinical practice guidelines for hepatocellular carcinoma: the Japan Society of Hepatology 2013 update (3rd JSH-HCC guidelines). Hepatol Res. 2015;45:123-7.

2. Wakabayashi G, Ikeda T, Otsuka Y, Nitta H, Cho A, Kaneko H. General gastroenterological surgery 3: liver. Asian J Endosc Surg. 2015;8:365-73,

3. Global Burden of Disease Cancer C, Fitzmaurice C, Allen C, Barber RM, Barregard L, Bhutta ZA, et al. Global, Regional, and National Cancer Incidence, Mortality, Years of Life Lost, Years Lived With Disability, and Disability-Adjusted Life-years for 32 Cancer Groups, 1990 to 2015: A Systematic Analysis for the Global Burden of Disease Study. JAMA Oncol. 2017;3:524-48. 
4. Varki A. Biological roles of oligosaccharides: all of the theories are correct. Glycobiology. 1993;3:97-130.

5. Ohtsubo K, Marth JD. Glycosylation in cellular mechanisms of health and disease. Cell. 2006;126:855-67.

6. Itzkowitz SH, Yuan M, Montgomery CK, Kjeldsen T, Takahashi HK, Bigbee WL, et al. Expression of Tn, sialosyl-Tn, and T antigens in human colon cancer. Cancer Res. 1989:49:197-204.

7. Ching CK, Holmes SW, Holmes GK, Long RG. Comparison of two sialosyl-Tn binding monoclonal antibodies (MLS102 and B72.3) in detecting pancreatic cancer. Gut. 1993;34:1722-5.

8. Carcel-Trullols J, Stanley JS, Saha R, Shaaf S, Bendre MS, Monzavi-Karbassi B, et al. Characterization of the glycosylation profile of the human breast cancer cell line, MDA-231, and a bone colonizing variant. Int J Oncol. 2006; 28:1173-83.

9. Christie DR, Shaikh FM, Lucas JA, Lucas JA 3rd, Bellis SL. ST6Gal-I expression in ovarian cancer cells promotes an invasive phenotype by altering integrin glycosylation and function. J Ovarian Res. 2008;1:3.

10. Abbott KL, Nairn AV, Hall EM, Horton MB, McDonald JF, Moremen KW, et al. Focused glycomic analysis of the N-linked glycan biosynthetic pathway in ovarian cancer. Proteomics. 2008;8:3210-20.

11. Liu YC, Yen HY, Chen CY, Chen CH, Cheng PF, Juan YH, et al. Sialylation and fucosylation of epidermal growth factor receptor suppress its dimerization and activation in lung cancer cells. Proc Natl Acad Sci U S A. 2011;108: 11332-7.

12. Taketa K, Sekiya C, Namiki M, Akamatsu K, Ohta Y, Endo Y, et al. Lectinreactive profiles of alpha-fetoprotein characterizing hepatocellular carcinoma and related conditions. Gastroenterology. 1990;99:508-18.

13. Masuda T, Miyoshi E. Cancer biomarkers for hepatocellular carcinomas: from traditional markers to recent topics. Clin Chem Lab Med. 2011;49:959-66.

14. Shang S, Li W, Qin X, Zhang S, Liu Y. Aided diagnosis of hepatocellular carcinoma using serum Fucosylated Haptoglobin ratios. J Cancer. 2017;8: 887-93.

15. Wang M, Long RE, Comunale MA, Junaidi O, Marrero J, Di Bisceglie AM, et al. Novel fucosylated biomarkers for the early detection of hepatocellular carcinoma. Cancer Epidemiol Biomark Prev. 2009;18:1914-21.

16. Hirabayashi J, Yamada M, Kuno A, Tateno H. Lectin microarrays: concept, principle and applications. Chem Soc Rev. 2013;42:4443-58.

17. Matsuda A, Kuno A, Ishida H, Kawamoto T, Shoda J, Hirabayashi J. Development of an all-in-one technology for glycan profiling targeting formalin-embedded tissue sections. Biochem Biophys Res Commun. 2008; 370:259-63.

18. Nakajima K, Inomata $\mathrm{M}$, Iha $\mathrm{H}$, Hiratsuka $\mathrm{T}$, Etoh T, Shiraishi $\mathrm{N}$, et al. Establishment of new predictive markers for distant recurrence of colorectal cancer using lectin microarray analysis. Cancer Med. 2015;4:293-302.

19. Futsukaichi T, Etoh T, Nakajima K, Daa T, Shiroshita H, Shiraishi N, et al, Decreased expression of Bauhinia purpurea lectin is a predictor of gastric cancer recurrence. Surg Today. 2015;45:1299-306.

20. Watanabe K, Ohta M, Yada K, Komori Y, Iwashita Y, Kashima K, et al. Fucosylation is associated with the malignant transformation of intraductal papillary mucinous neoplasms: a lectin microarray-based study. Surg Today. 2016:46:1217-23.

21. Oikawa T, Ojima H, Yamasaki S, Takayama T, Hirohashi S, Sakamoto M. Multistep and multicentric development of hepatocellular carcinoma: histological analysis of 980 resected nodules. J Hepatol. 2005;42:225-9.

22. International Consensus Group for Hepatocellular Neoplasia The International Consensus Group for Hepatocellular N. Pathologic diagnosis of early hepatocellular carcinoma: a report of the international consensus group for hepatocellular neoplasia. Hepatology. 2009;49:658-64.

23. An FQ, Matsuda M, Fujii H, Tang RF, Amemiya H, Dai YM, et al. Tumor heterogeneity in small hepatocellular carcinoma: analysis of tumor cell proliferation, expression and mutation of p53 AND beta-catenin. Int J Cancer. 2001;93:468-74.

24. Sakamoto M, Effendi K, Masugi Y. Molecular diagnosis of multistage hepatocarcinogenesis. Jpn J Clin Oncol. 2010;40:891-6.

25. Shibata R, Mori T, Du W, Chuma M, Gotoh M, Shimazu M, et al. Overexpression of cyclase-associated protein 2 in multistage hepatocarcinogenesis. Clin Cancer Res. 2006;12:5363-8.

26. Japan Liver Cancer Study Group of Japan. Histological classification of hepatocellular carcinoma. General Rules for the Clinical and Pathological Study of Primary Liver Cancer, Third English Edition. Tokyo: Kanehara; 2010. pp. 49-51.
27. GlycoTechnica. A list of lectins on LecChip Ver.1 and the specificity. Available from: http://www.glycotechnica.com/pdf/Lectin\%20Specificity_ with\%20layout.pdf. Accessed 17 Aug 2019.

28. Kuno A, Uchiyama N, Koseki-Kuno S, Ebe Y, Takashima S, Yamada M, et al. Evanescent-field fluorescence-assisted lectin microarray: a new strategy for glycan profiling. Nat Methods. 2005;2:851-6.

29. Rizzardi AE, Johnson AT, Vogel Rl, Pambuccian SE, Henriksen J, Skubitz AP, et al. Quantitative comparison of immunohistochemical staining measured by digital image analysis versus pathologist visual scoring. Diagn Pathol. 2012;7:42.

30. Wang X, Chen J, Li QK, Peskoe SB, Zhang B, Choi C, et al. Overexpression of a $(1,6)$ fucosyltransferase associated with aggressive prostate cancer. Glycobiology. 2014;24:935-44.

31. Mazzaferro V, Regalia E, Doci R, Andreola S, Pulvirenti A, Bozzetti F, et al. Liver transplantation for the treatment of small hepatocellular carcinomas in patients with cirrhosis. N Engl J Med. 1996;334:693-9.

32. Li X, Guan F, Li D, Tan Z, Yang G, Wu Y, et al. Identification of aberrantly expressed glycans in gastric cancer by integrated lectin microarray and mass spectrometric analyses. Oncotarget. 2016;7:87284-300.

33. Helenius A, Aebi M. Roles of N-linked glycans in the endoplasmic reticulum. Annu Rev Biochem. 2004;73:1019-49.

34. Kumar R, Stanley P. Transfection of a human gene that corrects the Lec1 glycosylation defect: evidence for transfer of the structural gene for $\mathrm{N}$ acetylglucosaminyltransferase I. Mol Cell Biol. 1989;9:5713-7.

35. Xu H, Guo H, Cheung IY, Cheung NKV. Antitumor efficacy of anti-GD2 IgG1 is enhanced by fc glyco-engineering. Cancer Immunol Res. 2016;4:631-8.

36. Ye Z, Marth JD. N-glycan branching requirement in neuronal and postnatal viability. Glycobiology. 2004;14:547-58.

37. Potapenko IO, Luders T, Russnes HG, Helland A, Sorlie T, Kristensen VN, et al. Glycan-related gene expression signatures in breast cancer subtypes; relation to survival. Mol Oncol. 2015;9:861-76.

38. Kang X, Wang N, Pei C, Sun L, Sun R, Chen J, et al. Glycan-related gene expression signatures in human metastatic hepatocellular carcinoma cells. Exp Ther Med. 2012;3:415-22.

39. Amin A, Bashir A, Zaki N, McCarthy D, Ahmed S, Lotfy M. Insights into glycan biosynthesis in chemically-induced hepatocellular carcinoma in rats: a glycomic analysis. World J Gastroenterol. 2015;21:6167-79.

40. Li S, Mo C, Peng Q, Kang X, Sun C, Jiang K, et al. Cell surface glycan alterations in epithelial mesenchymal transition process of Huh7 hepatocellular carcinoma cell. PLoS One. 2013;8:e71273.

41. Balog Cl, Stavenhagen K, Fung WL, Koeleman CA, McDonnell LA, Verhoeven A, et al. N-glycosylation of colorectal cancer tissues: a liquid chromatography and mass spectrometry-based investigation. Mol Cell Proteomics. 2012:11:571-85.

42. Sethi MK, Thaysen-Andersen M, Smith JT, Baker MS, Packer NH, Hancock WS, et al. Comparative N-glycan profiling of colorectal cancer cell lines reveals unique bisecting GICNAc and alpha-2,3-linked sialic acid determinants are associated with membrane proteins of the more metastatic/aggressive cell lines. J Proteome Res. 2014;13:277-88,

43. Wi GR, Moon Bl, Kim HJ, Lim W, Lee A, Lee JW, et al. A lectin-based approach to detecting carcinogenesis in breast tissue. Oncol Lett. 2016;11: 3889-95.

\section{Publisher's Note}

Springer Nature remains neutral with regard to jurisdictional claims in published maps and institutional affiliations.

\section{Ready to submit your research? Choose BMC and benefit from:}

- fast, convenient online submission

- thorough peer review by experienced researchers in your field

- rapid publication on acceptance

- support for research data, including large and complex data types

- gold Open Access which fosters wider collaboration and increased citations

- maximum visibility for your research: over $100 \mathrm{M}$ website views per year

At $\mathrm{BMC}$, research is always in progress.

Learn more biomedcentral.com/submissions 